\title{
Learning and Coping Strategies Through the Medium of a Second Official Language (012) Amongst Cameroonian University Students
}

\author{
Eyovi Njwe \\ The University of Bamenda, Cameroon
}

\begin{abstract}
A language of instruction is assumed to be an enabling tool that facilitates the learning of content subjects (Kyeyume 2010, Webb 2004). However, it turns out that, sometimes, some learners are made to study through the medium of a language in which they lack proficiency. When found in such circumstances, various mechanisms are employed to accomplish the task of learning the content subjects as well as improving the proficiency of the language of instruction. In this study, an investigation was carried out on the Francophone students of the Higher Technical Teacher Training College of the University of Bamenda in Cameroon, who carry out studies in Industrial and Tertiary subjects, through the medium of English language in which they lack proficiency, and which constitutes the second official language (OL2) for them. The first official language for these students is French, while their mother tongue which is their first language, is one of the indigenous Cameroonian Languages. To better understand the language condition, it is necessary to briefly present the diversified linguistic situation of Cameroon. Cameroon is a multilingual country with over 200 national languages. The nation practices exoglossic Bilingualism, instituted by the constitution. In this system, French and English which are vestiges of colonialism, are employed for communication. Four-fifths of Cameroon was colonized by France while one fifth was colonized by Britain. Consequently, upon their departure from Cameroon following the independence of the two regions, these languages, (French and English) were left behind by the various colonizing powers in their various spheres of influence. As a result of the many ethnic languages spoken by the people, French and English have turned out to be the only common languages available for inter-tribal use by the Cameroonians. This makes the French language the first official language (OL1) to the Francophone Cameroonians, and the English language is their second official language (OL2). Meanwhile to the Anglophone, the English language is the first official language (OL1) and French is the (OL2). In various regions, the medium of instruction in schools is the first official language.In this study, we present a situation where some Francophone students gain admission to study at tertiary levels in schools where English is the Medium of Instruction.
\end{abstract}


This research investigates the learning and coping strategies employed, to accomplish the task of learning. This research examines the degree of success in the learning process, as well as the difficulties encountered in the process. It also analysis the level of language proficiency improvement experienced by students, while studying in the second official language. A total of five hundred students were selected through the random sampling technique from over one thousand two hundred students. We employed the techniques of interviews, tests, and questionnaires, to obtain data for this study. Theories of Bilingualism and language acquisition were utilized. Findings and recommendations are provided to students, parents, teachers and the government.

Keywords: strategies, coping, second language, learning, Bilingualism education. 